\title{
THE ACCULTURATION MODEL OF SECOND LANGUAGE ACQUISITION: INSPECTING WEAKNESSES AND STRENGTHS
}

\author{
Alireza Zaker \\ Islamic Azad University, Science and Research Branch, Tehran, Iran \\ Email: alireza.zaker@gmail.com
}

APA Citation: Zakir, A. (2016). The acculturation model of second language acquisition: Inspecting weaknesses and strengths. Indonesian EFL Journal, 2(2), 80-87

Abstract: Previous research has highlighted the significant impact of culture on learning a second language (L2). Accordingly, culture is now believed to be a major learning-affecting factor which, along with linguistic competence, facilitates the process of L2 learning. Some have proposed that being surrounded in the L2 environment gives one a better chance of learning an L2. Based on this premise, Schumann in 1978 proposed the acculturation/pidginization model as an environmental-oriented model that emphasizes identification with a community as the primary requirement of second language acquisition. This study attempts to take a closer look at different aspects of this theory. The taxonomy of factors which control social distance is presented along with the different types of acculturation and the stages/steps of acculturation in an L2 environment. The article concludes with a discussion on the advantages and shortcomings of the model.

Keywords: acculturation, culture, pidginization, target language environment

\section{INTRODUCTION}

Learning a second language (L2) is now believed to be a multi-faceted phenomenon which is affected by numerous factors, ranging from internal to social and cultural factors (Hadley, 2003; Nosratinia \& Zaker, 2014, 2015; Zaker, 2015), and, consequently, many studies have highlighted the significant impact of culture on learning a second language (Fromkin, 2003; Zaker, 2016). Accordingly, culture is now believed to be a major learning-affecting factor which, along with linguistic competence, facilitates the process of $\mathrm{L} 2$ learning (Brown, 2007; Culhane, 2004; Fahim \& Zaker, 2014). Galloway (as cited in Hadley, 2003, p. 88) defines cultures as "powerful human creations, affording their members a shared identity, a cohesive framework for selecting, constructing, and interpreting perceptions, and for assigning value and meaning in consistent fashion."

Differences in intercultural communication lie partially in the culturally conditioned restraining forces on communication. Such intergroup differences can become prominent features of social interaction when members from different cultures communicate with each other (Macintyre, 2007). When it comes to English language, two major perspectives have been adopted; English as a lingua franca and a postmodern approach to English, which views it in hybrid and fluid terms. According to De Costa (2010), the former favors the interaction between different cultures through language whereas the latter acknowledges the existence of World English. 


\section{Alireza Zaker}

The Acculturation Model of Second Language Acquisition: Inspecting Weaknesses and Strengths

\section{The Acculturation Model}

Many have argued that the degree to which a learner is successful in second language acquisition (SLA) is dependent, to some degree, on how much contact the learner has with the L2 speakers (Schumann, 1986); therefore, it has been suggested that being surrounded in the L2 environment gives one a better chance of learning an L2 (Culhane, 2004). However, the way the first culture would be affected by this cultural change has been the subject of numerous studies. One famous longitudinal investigation was conducted by Schumann on some syntactic aspects with six learners ( 2 children, 2 adolescents, 2 adults) in which he used questionnaires, observed spontaneous conversation during ten months, and applied a quantitative treatment to the data (Menezes, 2013).

Based on the findings of the above mentioned study, Schumann (1978) proposed the acculturation/pidginization model, as an environmental-oriented model, which emphasizes identification with a community as a primary requirement of SLA. More specifically, Schumann (as cited in Long, 1990) argues that SLA is just one aspect of acculturation along with many others. Acculturation, according to Schumann (1986), is the social and psychological integration of the learner with the target language group. Schumann further states that any learner can be placed along a continuum ranging from social-psychological distance to social-psychological proximity with the speakers of the target language (Farhady, 1981).

Schumann's acculturation hypothesis, therefore, focuses on two main variables that account for differences in the way language learners approach and acquire language, social factors and psychological factors. They differ in that social variables account for the degree of social distance an L2 learner has to the target language whereas the psychological variables are concerned with an individual's response to the conditions they find themselves in their language learning (Ushioda, 1993).

Schumann and other theorists describe social distance as an individual's position or perceived position, in relation to the target language group, and the extent to which they become part of that target language group (Schumann, 1986; Damen, 1987; Ushioda, 1993; Ellis, 2008; Brown, 2007). Also, Schumann (as cited in Peirce, 1995) talks about social distance as being a key aspect to gauge the amount of acculturation, and hence how effective a learner is at picking up an L2. This distance is not static, but can be thought of as lying along a continuum from maximum distance to close proximity to the target language group. Schumann places both social and affective/psychological factors on similar scales, and makes the assertion that a learner's success in second language learning is dependent on the amount of acculturation; the degree to which they have reduced the social and psychological distance. Both Brown (2007) and Ushioda (1993) reinforce Schumann's idea that there is a significant and positive relationship between the depth of the social distance between two cultures and the difficulty in learning the $\mathrm{L} 2$ for the learner.

As stated above, the degree of language acquisition, based on this model, would correlate with the degree of the learner's proximity to the target group (Farhady, 1981; Jiang, Green, Henley, \& Masten, 2009). This point seems to have in common with Gardner and Lambert's (1959, p. 272) socioeducational model where they hypothesized that "a strong motivation to learn a second language follows from a desire to be accepted as a member of the new linguistic community." This notion 
has also been captured by concepts such as international posture (Yashima, 2002), xenophilic and sociocultural orientations (Clément, Dörnyei, \& Noels, 1994), and interest in the target language and people (Ushioda, 2001). According to Schumann (as cited in Ushioda, 1993), there is a taxonomy of factors which control social distance that determine how close an individual will come to becoming like the target language group. They are as follows:

1. Dominance/subordination: Relating to the perceived status of a group in relation to another;

2. Integration pattern: Assimilation (giving up your own lifestyle in favor of another) /acculturation/preservation (how much of your own culture you hold on to);

3. Degree of enclosure of both groups: Amount that the two groups share the same social facilities (low enclosure), or have different social facilities (high enclosure);

4. Degree of cohesiveness of second language learning group: intra group contacts (cohesive), or inter group contacts (non-cohesive);

5. Size of second language learning group;

6. Degree of congruence of the two cultures: The culture of the L2 group may be similar or different to the TL group; \&

\section{Inter-group attitudinal} evaluations: Positive or negative attitudes to each other.

The second factor mentioned by Schumann and put forward by Ellis (2008), psychological distance, relates to how comfortable a learner is in relation to the surrounding social affecting factors. Psychological distance disorientates a learner in a way that may cause them to resist opportunities to take full advantage of the social situation. Schumann in his 1975 article (as cited in Ushioda, 1993) lists five affective factors that may increase the psychological distance. They are:

\section{Language Shock: Disorientation} caused by learning a new linguistic system;

2. Culture Shock: Stress, anxiety and fear caused when entering a new culture, the routine activities suddenly become major obstacles;

3. Culture Stress: Prolonged culture shock, such as, homesickness, and questioning self-identity.

4. Motivation: Instrumental and integrative; and

5. Ego permeability: The degree to which an individual gives up their differences in favor of the target language group.

\section{Acculturation Types}

Schumann's model distinguished between two types of acculturation. In Type 1, the learner becomes socially integrated, developing social contacts with L2 speakers who provide him with input while continuing to retain the lifestyle and values of his native culture; this is similar to Berry's (as cited in Culhane, 2004) integration strategy. In Type 2 of acculturation, the learner develops social contacts in the target culture and also moves towards adopting the lifestyle and values of the target language group; this corresponds to Berry's (as cited in Culhane, 2004) assimilation strategy. By encompassing both definitions of acculturation, the model implies that a learner could succeed in acquiring the target language regardless of whether he chose to adopt the norms of the target culture or not (Bluestone, 2009).

Based on the above mentioned premise, it can be assumed that insufficient interaction with and input from target language speakers caused by 
low acculturation would result in a knowledge base that might contain representations of linguistic structure that are not correct by target language standards (Bialystok \& Sharwood Smith, as cited in Long, 1990). This phenomenon is known as pidginization part of this model. This hypothesis states if the social and/or psychological distance is great, then, acculturation is impeded and the learner does not progress beyond the early stages of language acquisition. As result, his/her target language will stay pidginized (Gitsaki, 1998).

Brown (1980) postulates the process of acculturation in the target language natural environment consists of four stages:

1. Euphoria: the learners get excited over the newness of the surroundings

2. Culture-shock: emerges as individuals feel the intrusion of more and more culture differences into their own images of self and security

3. Cultural stress and gradual recovery: some problems of acculturation are solved, while others continue for some time. The learner starts to understand the differences in thinking. The learner`s problems center around the question of identity; she/he does not perceive herself/himself as belonging to any culture.

4. Full-recovery: adaptation, assimilation, or acceptance of the new culture. A new identity is developed.

\section{The Acculturation Model and Input Hypothesis}

Krashen's input hypothesis attests to the advantages of receiving a lot of input, especially in the initial stages in language acquisition. Both the acculturation model and Krashen's
Monitor model try to lower a learner's affective filter, and hence make it possible for acquisition to take place. Where Schumann and other social linguists differ to Krashen is in the role of interaction as a key to success. Krashen's model appears to put the learner into quite a passive role whereas in the acculturation model the need to interact and be more active is quite evident (Mondy, 2007).

\section{Acculturation and Motivation}

It is Gardener's work on integrative and instrumental motivation that has been crucial in laying the foundations for the acculturation model. It is necessary to not only consider the general attitude of the learner, but how important they see the need to interact in the target language and with members of the target language culture so that opportunities can open up for interaction to take place, thereby reducing the social distance. It was Berry (as cited in Culhane, 2004) who furthered the idea of motivation within a social context with a model of acculturation attitudes, including the following factors:

- Integration (wanting to maintain their first culture and extend relations with new culture)

- Assimilation (wanting to integrate into new culture)

- Separation (wanting to maintain their own culture)

- Marginalization (little concern)

The difference between Schumann and Berry is that both of Schumann's categories assume that there is social contact between the learner and members of the target culture, whereas Berry's taxonomy allows for the possibility of limited or zero contact between groups (Bluestone, 2009).

Culhane (2004) discusses different kinds of motivation, and adds a third category to Gardener's traditional 
psychological variables, that of psychosocial motivation. The intercultural interaction model joins together Gardener's instrumental and integrative motivation under the new label of orientation. Culhane (2004) argues that Gardener's two themes on motivation should be extended to include assessment of the learner perceptions of the importance of using L2 in cultural communities.

Learners with a stronger instrumental motivation are likely to feel the educational setting alone is sufficient to accomplish their linguistic goals in acquiring the L2. They are expected, therefore, to make less effort to interact with members of the cultural group who use the L2. In contrast, learners with a higher degree of integrative motivation are likely to make more extensive efforts to form bonds with culturally different others when given the opportunity, as a means of learning the linguistic and cultural knowledge needed for sociocultural competence (Culhane, 2004).

\section{Contextual Support for the Acculturation Model}

Lybeck (2002) tested Schumann's acculturation theory via the operable social exchange networks model, which has a postmodern view on using English (De Costa, 2010), with English native speakers who acquired Norwegian as their L2 and found that those who developed positive network connections with native Norwegian speakers evidenced more native-like Norwegian pronunciation than those who had greater difficulty establishing such.

Hansen (1995) measured Germanborn American immigrants' acculturation on the variables identified in Schumann's acculturation model and found that acculturation correlated with native-like phonation of successful olderarrival age speakers that was assessed in both careful reading and spontaneous speech tasks. However, it should be stated that past research has indicated that the optimal acculturation strategy varies greatly by context with regard to the $\mathrm{L} 2$ acquisition practices and learning circumstances (Vedder \& Virta, 2005).

\section{Limitations of the Acculturation Model}

Although some studies favored the validity of the acculturation model, like those stated above, Schumann's theory received limited empirical support and faced strong criticism. As a fundamental criticism against the significance of cultural factors in SLA, Dash (as cited in Mondy, 2007) argues that cultural aspects are quite often, not so readily identifiable, and that individuals may succeed in SLA despite the social conditions. Moreover, according to Mondy (2007), there are some learners that will be determined to succeed, irrespective of any of the conditions that present themselves, and those learners that will not be successful, regardless of favorable social circumstances. This implies that individual learner differences, such as learning style and affective state are more distinguishable as attributing factors to SLA, than the social conditions (Mondy, 2007). Therefore, we should avoid making generalization about the importance of cultural factors.

Another problem with applying the acculturation model or in talking about macro-level group-to-group relationships in general, may be that these analyses take into account only one dimension of the many levels of relationships experienced by learners. A more complete picture may be achieved by including the micro-level effects of an individual's personal social network (Bluestone, 2009).

This model has also been criticized for deliberately excluding other potentially important variables (such as 


\section{Alireza Zaker}

The Acculturation Model of Second Language Acquisition: Inspecting Weaknesses and Strengths

cognitive and instructional factors) in SLA (Farhady, 1981). According to this model, variables other than acculturation are of minor or moderate importance for SLA (Farhady, 1981). For instance, this model does not provide any explanation or insight into the internal processes responsible for the acquisition of an $\mathrm{L} 2$. That is, it does not attempt to explain why there are developmental sequences or acquisition orders, for example, and what causes them (Tavakoli, 2013).

As another instance, this model argues that instruction has no important role in SLA (except for a few exceptional cases). In this regard, Schumann (as cited in Long, 1990, p. 31) states:

Educational institutions are really only free to manipulate teacher, method, and text variables. I believe that these variables are so weak in terms of the total language learning situation that no matter how much we attempt to change them, we will never achieve much more success than we are achieving now.

Among other criticisms that the acculturation theory received was that social factors are assumed to have a direct impact on SLA while they are more likely to have an indirect one (Ellis, 2008). Also, pidginization is a group phenomenon, while language acquisition is an individual phenomenon. Moreover, the acculturation model fails to explain how the social factors influence the quality of contact the learners experience (Ellis, 2008). Therefore, some people caution against placing social factors so clearly in the forefront as a separate entity.

Moreover, there remain some unanswered questions regarding the model. Schumann himself states that the model only accounts for language learning under conditions of immigration. He also cautions the reader about variables other than acculturation which may influence SLA. Schumann believes that the development of a typology of variables is important and must be continued. It is not clear, however, how long or to what extent the continuation of such typologies is necessary (Farhady, 1981).

Research-wise, it has been argued that if acculturation can be considered as a unique aspect of SLA, it has to be clearly classified and there needs to be some ways of measuring the amount of acculturation that is necessary for successful SLA. The model is problematic, however, in that the concept of acculturation and what it entails is too complex to be operationally defined and experimentally tested (Farhady, 1981). Put another way, although this model acknowledges that the degree of social distance between cultural groups can affect language learning, it does not provide a means of actually measuring social distance. In addition, because the model deals with cultural groups rather than individual learners, it is not useful for accounting for individual differences in learning outcomes (Bluestone, 2009).

\section{CONCLUSION}

As stated above, there have been many factors assumed to limit and question the applicability and validity of the acculturation model; yet, aspects of this model may have significant educational implications for SLA. That is why Stern (1983, p. 518) believes this model has given a "better insight into language learning, designing research studies, and diagnoses individual patterns of language learning." According to Spolsky (1988), successful L2 teaching requires not only the ability to impart grammatical knowledge, but also sensitivity to the social realities faced by students. Therefore, integrating cultural instruction in order to increase learners' cultural tolerance, cultural literacy, and native culture appreciation not only 
becomes a priority for L2 instructors but also for syllabus designers and policy makers.

Adopting such a context-sensitive perspective might generate higher levels of willingness and motivation among L2 learners (Bluestone, 2009). It is also suggested not to consider teachers and language instruction a substitute for a naturalistic context where personal experience would facilitate cultural literacy (Barjasteh \& Vaseghi, 2012). All in all, it seems reasonable to argue that cultural approximation would not guarantee the development of SLA; however, including cultural points in L2 programs can bring about considerable advantages if enough care and contextsensitivity is exercised.

\section{REFERENCES}

Bluestone, K. (2009). Acculturation, interpersonal networks, and the learner's sense of self: The effects of social relationships on secondlanguage learning. Working Papers in TESOL and Applied Linguistics, 9(2), 135-164.

Brown, H. D. (1980). The optimal distance model of second language learning. TESOL Quarterly, 14(2), 157-164. DOI: $10.2307 / 3586310$

Brown, H. D. (2007). Principles of language learning and teaching (5th ed.). New York: Pearson Education.

Culhane, S. F. (2004). An intercultural interaction model: Acculturation attitudes in second language acquisition. Electronic Journal of Foreign Language Teaching, 1(1), 5061.

Clément, R., Dörnyei, Z., \& Noels, K. (1994). Motivation, self-confidence and group cohesion in the foreign language classroom. Language Learning, 44, 417- 448. DOI: $10.1111 / \mathrm{j} .1467-$ 1770.1994.tb01113.x

Damen, L. (1987). Culture learning: The fifth dimension in the language classroom. Massachusetts: Addison-Wesley.
Ellis, R. (2008). The study of second language acquisition (2 ${ }^{\text {nd }}$ ed.). Oxford: Oxford University Press.

Fahim, M., \& Zaker, A. (2014). EFL learners' creativity and critical thinking: Are they associated? Humanising Language Teaching, 16(3). Retrieved from http://www.hltmag.co.uk/jun14/mart 01.htm

De Costa, P. I. (2010). Let's collaborate: Using developments in global English research to advance socioculturallyoriented SLA identity work. Issues in Applied Linguistics, 18(1), 99-124.

Farhady, H. (1981). On the plausibility of second language acquisition models. Retrieved September 19, 2014 http://mpazhou.ir/wpcontent/uploads/2011/11/On-thePlausibility-of-SLA-Models.pdf

Fromkin, V., Rodman. R., \& Hyams. N. (2003). An introduction to language. Massachusetts: Heinle.

Gitsaki, C. (1998). Second language acquisition theories: Overview and evaluation. Journal of Communication and International Studies, 4(2), 89-98.

Hansen, D. (1995). A study of the effect of the acculturation model on second language acquisition. In F. R. Eckman, D. Highland, P.W. Lee, J. Mileham \& R. Weber (Eds.), Second language acquisition theory and pedagogy (305316). Hillsdale, NJ: Lawrence Erlbaum.

Jiang, M., Green, R. J., Henley, T. B., \& Masten, W. G. (2009). Acculturation in relation to the acquisition of a second language. Journal of Multilingual and Multicultural Development, 30(6), 481492. DOI: $10.1080 / 01434630903147898$

Long, M. H. (1990). The least a second language acquisition theory needs to explain. TESOL Quarterly, 24(4), 649666. DOI: $10.2307 / 3587113$

Lybeck, K. (2002). Cultural identification and second language pronunciation of Americans in Norway. The Modern Language Journal, 86, 174-191. DOI: 10.1111/1540-4781.00143\

Macintyre, P. D. (2007). Willingness to communicate in the second language: Understanding the decision to speak as 
The Acculturation Model of Second Language Acquisition: Inspecting Weaknesses and Strengths

a volitional process. The Modern

Language Journal, 91(4), 564-576.

DOI: $10.1111 / \mathrm{j} .1540-$

4781.2007.00623.x

Menezes, V. (2013). Second language acquisition: Reconciling theories. Open Journal of Applied Sciences, 3, 404-412. DOI: $10.4236 /$ ojapps.2013.37050

Mondy, S. (2007). The acculturation model: A look into socio/psycho perspectives of SLA. Retrieved September 20, 2014 http://www.osk-ymca-intl.ed.jp

Nosratinia, M., \& Zaker, A. (2014).

Metacognitive attributes and liberated progress: The association among second language learners' critical thinking, creativity, and autonomy. SAGE Open, 4(3), 1-10. DOI: $10.1177 / 2158244014547178$

Nosratinia, M., \& Zaker, A. (2015). Boosting autonomous foreign language learning: Scrutinizing the role of creativity, critical thinking, and vocabulary learning strategies. International Journal of Applied Linguistics and English Literature, 4(4), 86-97. DOI:

10.7575/aiac.ijalel.v.4n.4p.86

Peirce, B. (1995). Social identity, Investment, and Language learning. TESOL Quarterly, 29(1), 9-31. DOI: $10.2307 / 3587803$

Schumann, J. H. (1978). The acculturation model for second language acquisition. In R. C. Gingras (Ed.), Second language acquisition and foreign language teaching (27-50). Washington: Center for Applied Linguistics.

Schumann, J. H. (1986). Research on the acculturation model for second language acquisition. Journal of Multilingual \& Multicultural Development, 7(5), 379-392. DOI: 10.1080/01434632.1986.9994254

Schumann, J. H. (1990). Extending the scope of the acculturation/pidginization model to include cognition. TESOL Quarterly, 24(4), 667-684. DOI: $10.2307 / 3587114$

Stern, H. H. (1983). Fundamental concepts of language teaching. Oxford: Oxford University Press.

Tavakoli, H. (2013). A dictionary of language acquisition: A comprehensive overview of key terms in first and second language acquisition. Tehran: Rahnama Press.

Ushioda, E. (1993). Acculturation theory and linguistic fossilization: A comparative case study. Dublin: Trinity College.

Ushioda, E. (2001). Language learning at university: Exploring the role of motivational thinking. In Z. Dörnyei \& R. Schmidt (Eds.), Motivation and second language acquisition (93-125). Honolulu: University of Hawaii.

Vedder, P., \& Virta, E. (2005). Language, ethnic identity, and the adaptation of Turkish immigrant youth in the Netherlands and Sweden. International Journal of InterculturalRelations 29, 317-337. DOI: 10.1016/j.ijintrel.2005.05.006

Yashima, T. (2002). Willingness to communicate in a second language: The Japanese EFL context. Modern Language Journal, 86, 54-66. DOI: $10.1111 / 1540-4781.00136$

Zaker, A. (2015). EFL learners' language learning strategies and autonomous learning: Which one is a better predictor of L2 skills? Journal of Applied Linguistics-Dubai, 1(1), 27-39.

Zaker, A. (2016). Social constructivism and metacognition in an EFL context: Inspecting the contribution of critical thinking to EFL learners' social intelligence. Humanising Language Teaching, 18(6). Retrieved from www.hltmag.co.uk/dec16/index.htm 